\section{Homens, masculinidade e violência: estudo em serviços de atenção primária à saúde}

\section{Men, masculinity and violence: $a$ study in primary health care services}

\section{Lilia Blima Schraiber \\ Claudia Renata dos Santos Barros \\ Márcia Thereza Couto \\ Wagner Santos Figueiredo \\ Fernando Pessoa de Albuquerque}

Departamento de Medicina Preventiva da Faculdade de Medicina da Universidade de São Paulo - FMUSP.

Pesquisa financiada pela Fundação de Amparo à Pesquisa do Estado de São Paulo, FAPESP (Proces so n.02/00413-9). Aprovada por Comitê de Ética da Pesquisa em 11/12/2002 protocolo n. 965/02 Correspondência: Lilia Blima Schraiber. Departamento de Medicina Preventiva, Faculdade de Medicina da USP. Av. Dr. Arnaldo, 455, $2^{\circ}$ andar, sala 2170, Cerqueira César, São Paulo, SP, Brasil CEP 01246-903. E-mail: liliabli@usp.br ou vawbr@usp.br

\section{Resumo}

Há poucos estudos sobre homens abordando violência como evento não fatal. Contribuindo nessa direção, descrevem-se as prevalências da violência psicológica, física e/ou sexual sofridas por homens, detalhando-se nestes tipos a perpetrada contra parceiras. Trata-se de estudo transversal realizado com 789 homens de 18 a 60 anos, dos quais 775 com alguma parceria íntima na vida, selecionados por ordem de chegada em dois serviços de atenção primária na cidade de São Paulo. Foram investigadas as características sociodemográficas e as violências mencionadas, examinadas ainda quanto a sobreposições e à percepção de havê-las sofrido ou perpetrado. As prevalências de violências sofridas na vida foram de $79 \%$ para qualquer tipo e por qualquer agressor; $63,9 \%, 52,8 \%$ e $6,1 \%$ respectivamente para psicológica, física e sexual. Para violências perpetradas contra a parceira na vida, temos $52,1 \%$ qualquer tipo e $40 \%, 31,9 \%$ e $3,9 \%$, respectivamente, para violência psicológica, física e sexual. Nas sofridas e nas perpetradas, a psicológica é a de maior taxa exclusiva, seguida da física. Quanto aos agressores, conhecidos é o principal agressor, seguido de familiar, estranhos e parceira íntima. Na relação entre sofrer por suas parceiras e perpetrar, $14,2 \%$ dos casos são sobrepostos e 81,2\% somente perpetraram. Conclui-se que, embora nas violências relativas às parceiras íntimas os homens sofram muito menos do que perpetrem, os dados mostram que eles se envolvem em muitas situações de violência, de grandes magnitudes e sobreposições, quer como vitimas ou agressores, reiterando estudos sobre masculinidade. Este conjunto complexo de situações também deve ser considerado nos serviços básicos de saúde.

Palavras-chave: Homens. Masculinidade. Gênero. Violência. Serviços de saúde. Atenção Primária. 


\section{Abstract}

There are few studies on men dealing with violence as a non-fatal event. As a contribution, the prevalences of psychological, physical and/or sexual violence suffered by men and the perpetrated intimate partner violence (IPV) are described. This was a cross-sectional study on 789 men aged 18 to 60 years, of whom 775 ever partnered. Men were selected in order of arrival at two primary healthcare clinics in the city of São Paulo. Sociodemographic characteristics and reported violence were investigated, along with the violence overlapping and perceptions of having suffered or perpetrated violence. The lifetime prevalence of suffered violence was $79 \%$ for any type and any aggressor; $63.9 \%, 52.8 \%$ and $6.1 \%$ respectively for psychological, physical and sexual violence. For lifetime IPV, the rates were $52.1 \%$ for any type and $40 \%, 31.9 \%$ and $3.9 \%$ respectively for psychological, physical and sexual violence. For both suffered and perpetrated violence, the psychological type had the highest exclusive rate, followed by physical. Acquaintances were the main aggressors, followed by family members, strangers and female intimate partners. Between suffering and perpetrating IPV, $14.2 \%$ of the cases overlapped and $81.2 \%$ consisted only of perpetrated violence. It was concluded that although in relation to intimate partner violence, men suffered much less than they perpetrated, the data showed that they were involved in many situations of violence of large magnitude and overlapping situations, both as victims and as aggressors, thus echoing studies on masculinity. This complex set of situations should also be taken into consideration in primary healthcare services.

Keywords: Men. Masculinity. Gender. Violence. Health services. Primary Care.

\section{Introdução}

As conexões entre violência e saúde são estudadas desde a década de 1970, com progressivos esforços de aprimoramentos teórico-metodológicos e, em paralelo, empenho político voltado à visibilidade dos agravos à saúde e à formulação de políticas de enfrentamento ${ }^{1}$. Revisão sobre estudos científicos tratando da violência no campo da saúde ${ }^{2}$ mostra o importante papel desempenhado por aqueles que mensuram a magnitude dos distintos tipos de violência, tal como os estudos de prevalência.

No entanto, da perspectiva da população masculina, os primeiros estudos na Saúde são os que partem dos indicadores de mortalidade. A relação dos homens com a violência mais examinada é a dos perfis de mortes, em estudos sobre as 'causas externas', dentre as quais estão os homicídios e os suicídios, que se definem desde 2002 pela Organização Mundial da Saúde (OMS) como mortes violentas ${ }^{3}$. No Brasil, buscando investigar dados de registro sistemático de informação e ainda se mantendo no recorte das 'causas externas', surgem também estudos das internações hospitalares devidas a essas causas, o que se pode considerar como uma primeira aproximação da violência como evento não fatal ${ }^{2}$.

A partir dos anos 2000, ao se postular a necessidade da inclusão dos homens nas propostas de intervenção para barrar o ciclo de violência entre os gêneros ${ }^{4-6}$, observa-se a necessidade de maior conhecimento acerca do polo masculino nessas violências não fatais, com destaque às do tipo doméstico. Os primeiros estudos, qualitativos, pesquisam as representações dos homens sobre o exercício de poder nas relações afetivo-conjugais e suas conexões com a violência, discutindo esta como parte da construção da identidade social masculina hegemônica: a masculinidade tida culturalmente como referência ${ }^{7-11}$.

De modo geral existem poucos estudos que estimam as prevalências das diversas situações de violência não fatal em que os homens se envolvem. Pesquisas 
americanas ${ }^{12,13}$ mostram que tais situações ocorrem principalmente nos espaços públicos e os homens se alternam nas posições de agressores e agredidos, sendo a violência física a que mais caracteriza o tipo de violência por eles sofrida ${ }^{14,15}$.

Menos explorados e em produção mais recente, contrastando com a temática da violência contra mulheres, são os estudos conduzidos com homens e que enfocam, para além da violência sofrida, a violência perpetrada no âmbito doméstico ${ }^{16,17}$.

Com o objetivo de ampliar o conhecimento desses dois tipos de situação relativamente aos homens, quer a violência sofrida, quer a perpetrada, e em especial objetivando estimar aquela perpetrada contra suas parceiras íntimas, realizamos uma pesquisa no período 2002-2004, com homens usuários de serviços de saúde de 18 a 60 anos. Os primeiros resultados foram publicados em análises de gênero ${ }^{18}$, discutindo-se os comportamentos violentos dos homens como exercícios de diversas masculinidades, nos domínios da vida pública e da vida privada.

Do conjunto do estudo, neste artigo são apresentadas: as prevalências de violências psicológica, física e sexual sofridas por homens e discriminadas por agressores; e as prevalências desses mesmos tipos de violência por eles praticadas especialmente contra sua parceira, atual ou anterior(es). Também se investigou aquela praticada contra outras pessoas que não a parceira, mas neste caso a violência abordada foi a do tipo físico. Ainda foram consideradas as superposições das violências, seja na situação de violência sofrida ou na de perpetrada, bem como na relação entre essas duas formas. E, tendo em vista que o termo violência tem sido apontado como polissêmico, pesquisou-se ainda a percepção da violência sofrida e da praticada.

\section{Material e método}

Estudo transversal com seleção de dois serviços de atenção primária por amostragem de conveniência, cujos critérios foram: significativa demanda populacional; existência de equipe multiprofissional com capacidade para acolher possíveis casos ativados pela pesquisa; qualidade dos registros médicos em prontuários; condições adequadas de espaço físico para o desenvolvimento das atividades de pesquisa; percepção do problema violência como necessidade de saúde por parte da chefia e das equipes; e ter pertencido a pesquisas de mesmo desenho e metodologia, abordando mulheres usuárias para fins de estudo comparativo futuro quanto à violência perpetrada pelos homens contra suas parceiras íntimas (atual esposa/companheira(o), ou qualquer outra companheira(o) ou namorada(o), com relacionamento afetivo-sexual).

A seleção amostral foi do tipo consecutivo, captando-se os participantes por ordem de chegada ao serviço, com repartição proporcional da amostra aos volumes de atendimento por dia da semana e período de atendimento. Foram elegíveis os que demandaram espontaneamente por atividades assistenciais na unidade, e os que, pertencendo à população adscrita ao serviço como potenciais usuários, acompanharam outras pessoas à unidade; todos esses, desde que apresentassem condições físicas e mentais para serem entrevistados. A violência não foi critério para a captação dos entrevistados e, por isso, não se produziu nenhum viés de seleção quanto a essa variável. Para cada recusa, outro usuário foi abordado, até se completar o tamanho da amostra.

O cálculo da amostra foi baseado em dados de duas pesquisas realizadas com mulheres no Município de São Paulo, uma em unidades básicas de saúde ${ }^{19} \mathrm{e}$ outra populacional ${ }^{20}$. Observou-se que com uma amostra de 786 usuários seria possível obter: Estimativas de prevalência de diferentes formas de violência conjugal atual e, consequentemente, a identificação da porcentagem de potenciais "agressores" e suas características sociodemográficas, sob uma precisão de $5 \%$ entre a prevalência estimada e o verdadeiro valor populacional e com $95 \%$ de confiança; Estimativas de razão de prevalência mínimas, as quais seriam 
alcançadas com um poder do teste de $80 \%$, ou seja, com uma chance de $80 \%$ de detectar diferenças entre usuários 'agressores' e 'não-agressores' a um nível de significância de $5 \%$, quanto a potenciais fatores de risco a que estariam sujeitos.

A coleta de dados foi feita por aplicação de questionário que identificou características sociodemográficas, aspectos de saúde reprodutiva e sexual, violência sofrida e praticada quanto aos tipos físico, psicológico e/ ou sexual. Para a violência praticada, como interesse principal do estudo como um todo, priorizou-se, em termos do detalhamento de tipos de violência, aquela perpetrada contra as parceiras íntimas ou esposas (atual ou anterior), o que foi perguntado para homens que tinham ou tiveram algum relacionamento do tipo parceria conjugal ou afetivo-sexual. Para cada uma das perguntas e nos três tipos de violência estudados, também foi abordado se os episódios ocorreram uma, poucas ou muitas vezes (recorrência ou repetição da violência). As perguntas não continham o termo violência e foram adaptadas do questionário valida$\mathrm{do}^{21}$ utilizado com mulheres. Iniciaram por: "O senhor poderia me dizer se alguma vez tratou a sua atual esposa/companheira(o), ou qualquer outra companheira(o) ou namorada(o) da seguinte forma", sendo complementadas por: 1) para a violência psicológica (1 item) - "Insultou, depreciou, humilhou ou fez com que ela(e) se sentisse mal”; 2) para a violência física (5 itens) - "1. deu-lhe um tapa ou atirou-lhe algo que poderia machucá-la? 2. empurrou-a ou deu-lhe um tranco/chacoalhão? 3. machucou-a com um soco ou com algum objeto? 4. deu-lhe um chute, arrastou-a ou surrou-a? 5. estrangulou-a ou queimou-a de propósito? 5. ameaçou usar ou realmente usou arma de fogo, faca ou outro tipo de arma contra ela?” ; 3) para a violência sexual (2 itens) - “ 1. obrigou sua parceira a ter relações sexuais quando ela não queria? 2. obrigou sua parceira a fazer certas práticas sexuais de que ela não gostasse?".

As perguntas com mais de um item (violência física e sexual) foram consideradas positivas desde que pelo menos um dos itens já fosse respondido afirmativamente. Tais perguntas mostraram-se consistentes com um Alpha de Cronbach de 0,89 para a pergunta do tipo físico e 0,86 para o sexual.

Os homens também foram questionados sobre a prática de violência na vida adulta contra outras pessoas. Mas neste caso apenas foi investigada a violência física, como se segue: "Após os seus 18 anos, você alguma vez já bateu ou agrediu fisicamente alguém que não a sua companheira?" Quanto às pessoas agredidas, as respostas foram categorizadas em: outro familiar que não a parceira; conhecidos (amigos, vizinhos e colegas de trabalho); estranhos.

Na violência sofrida, as perguntas formuladas também procuraram discriminar os atos de violência psicológica, física e sexual, mas sem discriminar seus itens internos. A violência sofrida também foi explorada quanto à recorrência dos episódios.

As perguntas feitas foram: 1. para a violência psicológica - "alguma vez, alguém (na rua, no bar, no trabalho ou em sua casa) já o insultou, depreciou, ou fez com que você se sentisse desvalorizado?"; 2 . para a violência física - "alguma vez, alguém (na rua, no bar, no trabalho ou em sua casa) já o agrediu fisicamente (com tapas, empurrões, socos, chutes, etc.)?"; e 3. para a violência sexual "alguma vez, alguém já o forçou a ter relação sexual contra sua vontade?".

Quanto aos agressores, as respostas foram categorizadas como se segue: parceira íntima; outro familiar que não a parceira; conhecidos (amigos, vizinhos e colegas de trabalho); estranhos.

Por fim, com o intuito de investigar a percepção do envolvimento em situações de violência por parte dos usuários entrevistados, foram feitas no final do questionário duas perguntas, as quais referiam, pela primeira vez, a palavra violência: 1) "você considera que sofreu violência por alguma pessoa na vida?"; 2) você considera que já foi violento com alguém na vida?"

A análise de dados realizada foi descritiva, sendo as variáveis descritas por meio de média, desvio padrão, frequências, 
proporções e intervalos de confiança, com o intuito de analisar a prevalência das violências sofridas e perpetradas. Foram ainda analisadas as sobreposições das violências física, sexual e psicológica, no caso da violência sofrida e no caso da violência perpetrada contra a parceira íntima. A relação entre os que sofreram e os que perpetraram violências, no recorte da parceria íntima, também foi examinada. As análises foram realizadas com o Stata 10.0.

A pesquisa foi aprovada pela Comissão de Ética da instituição responsável em 11/12/2002. A todos os participantes do estudo foram aplicados questionários por pesquisadores do sexo masculino, em entrevistas realizadas em locais privativos dos serviços mediante a leitura e assinatura do termo de consentimento livre e esclarecido (TCLE). Este e outros procedimentos de natureza ética em relação aos homens participantes da pesquisa foram adotados com base em recomendações para estudos de temas sensíveis ${ }^{23}$, tais como previsão de suporte assistencial e cuidados especiais na escolha, treinamentos e supervisão dos pesquisadores de campo.

\section{Resultados}

Foram entrevistados 789 usuários, sendo 775 com alguma parceria afetiva sexual na vida. A média de idade da amostra total foi de 35,8 anos ( $\mathrm{DP}=11,0)$. Com relação à escolaridade, a média geral de anos de estudo foi de 7,6 anos (DP =3,9), correspondendo ao nível fundamental incompleto. Um terço dos homens tinha de 25 a 34 anos e a maior concentração do nível de escolaridade ocorreu entre 5 a 11 anos de estudo (Tabela 1).

A maior parte dos entrevistados era trabalhador vinculado, seguido dos autônomos. Constatou-se proporção relevante de desempregados. A maioria tinha parceira no momento da entrevista. Destes, a maior parte se definiu como casado ou vivendo com companheira. Quanto à composição dos domicílios, a maior proporção dos homens reside em lares formados por família nuclear (casal com filhos).

\section{Os homens e a violência sofrida}

Observamos na Tabela 2 que é bastante elevada a prevalência de violência sofrida na vida, de qualquer tipo e por qualquer agressor. Quando se consideram os tipos psicológico, físico e sexual dessa violência sofrida, independente de sobreposições e considerando-se em separado cada tipo, têm-se respectivamente as taxas de $63,9 \%$ ( $\mathrm{n}=504), 52,8 \%(\mathrm{n}=416)$ e $6,1 \%(\mathrm{n}=48)$.

Quanto à recorrência, observa-se que a violência psicológica e a física caracterizam-se pela repetição dos episódios, se agregarmos poucas ou muitas vezes de ocorrência frente à ocorrência única (uma vez), embora a psicológica apresente sua maior magnitude de ocorrência na alta frequência (muitas vezes) e a física na ocorrência de uma vez. Já na violência sexual é a ocorrência única que a caracteriza, já que sua magnitude ultrapassa a soma das repetições em poucas e muitas vezes.

Quanto aos agressores (Figura 1), observa-se que na violência psicológica, colegas de trabalho, conhecidos e estranhos apresentam-se, nesta ordem, como os três principais agressores. Já na violência física surge outro padrão, com os familiares surgindo em segundo lugar, com estranhos, em ordem de importância como agressor. Esses dados mostram a forte presença dos colegas de trabalho na violência psicológica, mas não na violência física, cuja presença maior é a de pessoas mais próximas. $\mathrm{Na}$ violência sexual, observamos outro perfil, com a parceira íntima sendo a segunda categoria mais importante de agressor. De outro lado, nas violências física e psicológica, a parceira íntima é agressor bem menos importante.

\section{Os homens e a violência praticada}

Um terço dos homens $(\mathrm{n}=247 ; 31,3 \%)$ praticou violência física contra outras pessoas que não suas parceiras ou ex-parceiras íntimas (dados não apresentados). Quando categorizadas as pessoas agredidas, observamos que as principais vítimas das 
Tabela 1 - Frequências, proporções e intervalos de confiança das características sociodemográficas dos homens usuários dos serviços de saúde ( $N=789)$. São Paulo, 2003.

Table 1 - Frequencies, proportions and confidence intervals of socio demographic characteristics of men users of healthcare clinics ( $N=789$ ). São Paulo, 2003.

\begin{tabular}{|c|c|c|c|}
\hline Variáveis & $\mathrm{n}$ & $\%$ & IC 95\% \\
\hline \multicolumn{4}{|l|}{ Idade } \\
\hline De 18 a 24 anos & 160 & 20,3 & 17,$5 ; 23,1$ \\
\hline De 25 a 34 anos & 246 & 31,2 & 27,$9 ; 34,4$ \\
\hline De 35 a 44 anos & 197 & 25,0 & 21,$9 ; 27,9$ \\
\hline De 45 a 54 anos & 147 & 18,6 & 15,$9 ; 21,3$ \\
\hline De 55 a 60 anos & 39 & 4,9 & 3,$4 ; 6,4$ \\
\hline \multicolumn{4}{|l|}{ Anos de estudo } \\
\hline 0 a 4 & 193 & 24,5 & 21,$4 ; 27,5$ \\
\hline 5 a 8 & 267 & 33,8 & 30,$5 ; 37,1$ \\
\hline 9 a 11 & 250 & 31,7 & 28,$4 ; 34,9$ \\
\hline 12 ou mais & 79 & 10,0 & 7,$9 ; 12,1$ \\
\hline \multicolumn{4}{|l|}{ Situação Empregatícia } \\
\hline Estudante & 13 & 1,6 & 0,$07 ; 2,5$ \\
\hline Trabalho em empresa & 342 & 43,4 & 39,$8 ; 46,8$ \\
\hline Autônomo & 212 & 26,9 & 23,$7 ; 29,9$ \\
\hline Trabalho esporádico & 32 & 4,1 & 2,$6 ; 5,4$ \\
\hline Desempregado & 133 & 16,9 & 14,$2 ; 19,4$ \\
\hline Aposentado/pensionista & 39 & 4,9 & 3,$4 ; 6,4$ \\
\hline Outros & 18 & 2,2 & 1,$2 ; 3,3$ \\
\hline \multicolumn{4}{|l|}{ Situação Conjugal } \\
\hline Coabita com Parceira Sexual & 514 & 65,1 & 61,$8 ; 68,4$ \\
\hline Tem Parceira Sexual s/ coabitar & 123 & 15,6 & 13,$0 ; 18,1$ \\
\hline Solteiro & 152 & 19,3 & 16,$5 ; 22,0$ \\
\hline \multicolumn{4}{|l|}{ Composição do Domicílio } \\
\hline Casal com filhos e parentes & 111 & 14,1 & 11,$6 ; 16,4$ \\
\hline Casal com filhos sem parentes & 370 & 46,9 & 43,$4 ; 50,3$ \\
\hline Casal sem filhos & 74 & 9,4 & 7,$3 ; 11,4$ \\
\hline Sem cônjuge com família & 138 & 17,5 & 14,$8 ; 20,1$ \\
\hline Sozinho, c/ amigos ou outros & 96 & 12,1 & 9,$8 ; 14,4$ \\
\hline
\end{tabular}

agressões foram estranhos (44,9\%), seguido de conhecidos $(34,8 \%)$.

Já quanto à violência contra parceira íntima (Tabela 3), observamos que pouco mais da metade dos homens $(52,1 \%)$ perpetrou algum tipo de violência (psicológica, física e/ou sexual) na vida. Em relação ao tipo de violência perpetrada, pudemos observar que a maior prevalência foi a violência psicológica e física conjuntamente, seguida da exclusivamente psicológica.

Quanto à recorrência, observa-se que são os episódios de repetição a característica da violência psicológica, o que nos demais tipos oferece um perfil diverso ao apontar para magnitudes muito próximas entre o episódio único e as repetições. Chama a atenção que a repetição de episódios poucas vezes é a de maior frequência para a violência psicológica e para a sexual.

\section{Os homens e a sobreposição de violências}

Como se observa na Figura 2, há várias sobreposições verificadas nas situações de violência: as que se dão entre os tipos psicológico, físico e sexual, para as violências 
Tabela 2 - Prevalências das violências sofridas pelos homens e recorrências dos episódios. São Paulo, 2003.

Table 2 - Prevalences of violence against men and the recurrence of episodes. São Paulo, 2003.

\begin{tabular}{|c|c|c|c|}
\hline Violências (n=789) & $\mathrm{n}$ & (\%) & IC 95\% \\
\hline Não sofreu & 166 & 21,0 & 18,$2 ; 23,9$ \\
\hline Exclusivamente Psicológica & 187 & 23,7 & 20,$7 ; 26,7$ \\
\hline Exclusivamente Física & 109 & 13,8 & 11,$4 ; 16,2$ \\
\hline Exclusivamente Sexual & 8 & 1,0 & 0,$3 ; 1,7$ \\
\hline Psicológica e Física & 279 & 35,4 & 32,$0 ; 38,7$ \\
\hline Psicológica e Sexual & 12 & 1,5 & 0,$7 ; 2,4$ \\
\hline Física e Sexual & 2 & 0,3 & 0,$09 ; 0,6$ \\
\hline Todas & 26 & 3,3 & 2,$0 ; 4,5$ \\
\hline Qualquer Tipo & 623 & 79,0 & 76,$1 ; 81,8$ \\
\hline RECORRÊNCIAS & $\mathrm{n}$ & (\%) & IC 95\% \\
\hline \multicolumn{4}{|l|}{ Psicológica $(n=784) *$} \\
\hline Não sofreu & 285 & 36,3 & $(32,9 ; 39,7)$ \\
\hline Uma vez & 145 & 18,5 & $(15,8 ; 21,2)$ \\
\hline Poucas vezes & 147 & 18,7 & $(16,0 ; 21,5)$ \\
\hline Muitas vezes & 207 & 26,4 & $(23,3 ; 29,5)$ \\
\hline \multicolumn{4}{|l|}{ Física $(n=789)$} \\
\hline Não sofreu & 373 & 47,3 & $(43,8 ; 50,8)$ \\
\hline Uma vez & 162 & 20,5 & $(17,7 ; 23,3)$ \\
\hline Poucas vezes & 129 & 16,4 & $(13,7 ; 18,9)$ \\
\hline Muitas vezes & 125 & 15,8 & $(13,2 ; 18,4)$ \\
\hline \multicolumn{4}{|l|}{ Sexual $(n=788) *$} \\
\hline Não sofreu & 741 & 94,0 & $(92,4 ; 95,7)$ \\
\hline Uma vez & 32 & 4,1 & $(2,7 ; 5,4)$ \\
\hline Poucas vezes & 10 & 1,3 & $(0,5 ; 2,1)$ \\
\hline Muitas vezes & 5 & 0,6 & $(0,08 ; 1,2)$ \\
\hline
\end{tabular}

* Na violência psicológica há 05 perdas e na sexual há 01 perda / * There are 05 missings for psychological violence and 01 missing for sexual violence

perpetradas e também no caso das sofridas. Mas há ainda a sobreposição entre sofrer e perpetrar violências.

Na sobreposição das violências sofridas pelos homens, aquela de maior proporção entre os casos relatados é a violência psicológica associada à física. $\mathrm{O}$ tipo exclusivo mais presente entre os casos é a violência psicológica (30\% dos casos), sendo rara a situação de violência sexual exclusiva. A sobreposição dos três tipos é proporcionalmente a situação de menor ocorrência.

$O$ perfil relatado da violência sofrida aproxima-se daquele que se observa para os casos de violência praticada contra a parceira íntima, sendo, nesta última, ainda mais presente o tipo psicológico exclusivo
(35,6\% dos casos de violência). Como na violência sofrida, na praticada, ainda que o seja contra a parceira íntima, também a violência sexual raramente é exclusiva.

Já considerando a relação entre sofrer e perpetrar violências, tomando-se apenas os que sofreram e perpetraram relativamente a suas parceiras íntimas ( $\mathrm{n}=775)$, observou-se que há uma sobreposição de 14,2\% dos casos, sendo que a grande maioria das situações são as de violência exclusivamente perpetrada $(81,3 \%)$.

\section{Os homens e a percepção de terem sofrido ou perpetrado violência}

Quando questionados se consideraram 
Violência Psicológica

$(n=499)$

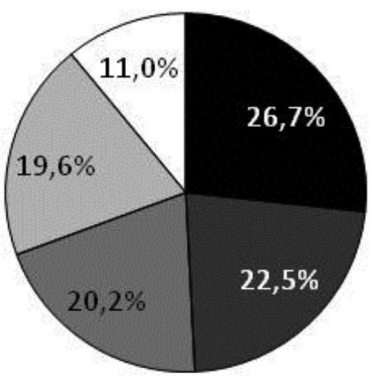

Violência Física

$(n=416)$

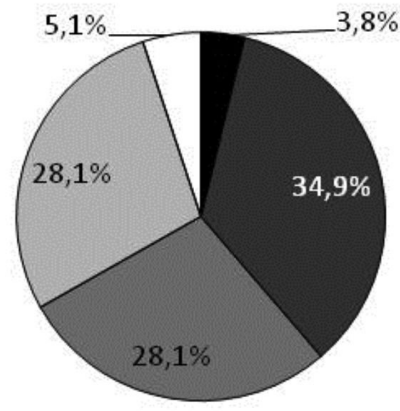

Violência Sexual

$(n=47)$

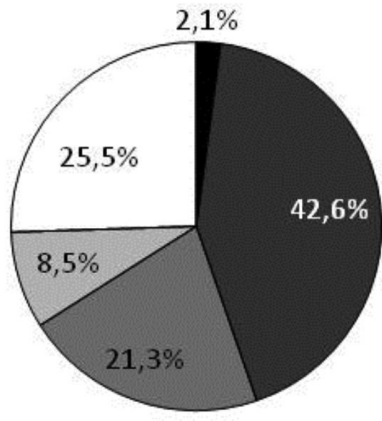

$\square$ Colegas de trabalho
$\square$ Familiares

Conhecidos (vizinhose amigos)

Estranhos

Parceira

Notas:

Na violência psicológica 5 casos e na sexual um caso sem resposta quanto a agressores; outros agressores ( 14 na psicológica, 5 na física e 4 na sexual) pela baixa frequência estăo agrupados com estranhos.

Figura 1 - Tipo de violências sofridas pelos homens segundo agressores. São Paulo, 2003.

Figure 1 - Types of violence against men by aggressor. São Paulo, 2003.

ter sofrido violência na vida, independentemente de indicar os agressores, $67,2 \%$ dos homens entrevistados responderam que não, enquanto $32,8 \%$ que sim. Na percepção de terem sido violentos na vida, independentemente de indicarem contra quem o teriam sido, observamos padrão similar de resposta, com $69,6 \%$ não considerando terem sido violentos e $30,4 \%$ afirmando terem sido violentos.

\section{Discussão}

O presente estudo é pioneiro no Brasil no estudo da violência não fatal sofrida e perpetrada por homens, considerando simultaneamente as relações de conjugalidade ou parceria e outras do espaço privado e público. Mostra as altas taxas de violência na população pesquisada e o contingente volumoso de usuários no interior dos serviços de saúde, em particular nos de atenção primária, que constituem casos de violência sofrida ou casos de homens agressores. Embora tenha como limitações a amostra por conveniência, pesquisar apenas homens usuários e ter sido desenhado prioritariamente para a violência perpetrada contra a parceira íntima, o presente estudo permitiu a coleta fidedigna de diversas situações de violências, sofridas e perpetradas.

Com relação à violência praticada, mesmo em se tratando daquela perpetrada contra outros que não a parceira, verifica-se prevalência de elevada magnitude, o que já aponta para a reprodução do padrão cultural hegemônico de socialização masculina $^{17,22,24}$ e reitera outros estudos, com amostras populacionais a partir de 18 anos $^{12,13}$. Neste estudo os dados mostram, igualmente, que essa violência ocorre em espaços públicos e ambientes coletivos de relativo anonimato, sendo também contra 'estranhos' nossa maior frequência de $\operatorname{casos}^{12,13}$.

A taxa de qualquer tipo de violência perpetrada contra a parceira é compatível com os dados apontados em revisão brasileira ${ }^{17}$. Esta refere que Barker e Acosta, em 2003, pesquisando 749 homens de 15 a 60 anos, 
Tabela 3 - Prevalências das violências perpetradas contra a parceira intima e recorrências de episódios. São Paulo, 2003.

Table 3 - Prevalences of perpetrated violence against intimate partner and the recurrence of episodes. São Paulo, 2003.

\begin{tabular}{lccc}
\hline Violências ( $\mathrm{n}=775)$ & $\mathrm{n}$ & $(\%)$ & $\mathrm{IC} 95 \%$ \\
\hline Não praticou & 371 & 47,9 & 44,$3 ; 51,4$ \\
Exclusivamente Psicológica & 144 & 18,6 & 15,$8 ; 21,3$ \\
Exclusivamente Física & 82 & 10,5 & 8,$4 ; 12,7$ \\
Exclusivamente Sexual & 9 & 1,2 & 0,$4 ; 1,9$ \\
Psicológica e Física & 148 & 19,1 & 16,$3 ; 21,9$ \\
Psicológica e Sexual & 4 & 0,5 & 0,$01 ; 1,0$ \\
Física e Sexual & 3 & 0,4 & 0,$05 ; 0,8$ \\
Todas & 14 & 1,8 & 0,$8 ; 2,7$ \\
Qualquer Tipo & 404 & 52,1 & 48,$7 ; 55,7$ \\
\hline RECORRÊNCIAS & $\mathrm{n}$ & $(\%)$ & $\mathrm{IC} 95 \%$ \\
\hline Psicológica & & & \\
$\quad$ Não sofreu & 465 & 60,0 & $(56,5 ; 63,4)$ \\
$\quad$ Uma vez & 77 & 9,9 & $(7,8 ; 12,0)$ \\
$\quad$ Poucas vezes & 159 & 20,5 & $(17,7 ; 23,4)$ \\
$\quad$ Muitas vezes & 74 & 9,6 & $(7,5 ; 11,6)$ \\
Física & & & \\
$\quad$ Não sofreu & 528 & 68,1 & $(64,8 ; 71,4)$ \\
$\quad$ Uma vez & 130 & 16,8 & $(14,1 ; 19,4)$ \\
$\quad$ Poucas vezes & 85 & 11,0 & $(8,8 ; 13,1)$ \\
$\quad$ Muitas vezes & 32 & 4,1 & $(2,7 ; 5,5)$ \\
Sexual ** & & & $(95,0 ; 97,7)$ \\
$\quad$ Não sofreu & 745 & 96,4 & $(0,6 ; 2,2)$ \\
$\quad$ Uma vez & 11 & 1,4 & $(0,9 ; 2,7)$ \\
$\quad$ Poucas vezes $\quad$ Muitas vezes & 1,8 & $0,05 ; 0,8)$ \\
\hline Entstos & 0,4 & \\
\hline
\end{tabular}

* Entrevistados casados que moram com a companheira, que tem namorada ou que alguma vez na vida tiveram relacionamento desse tipo. ${ }^{* *} 2$ perdas

* Married interviewees who lived with a companion, who had a girlfriend or had this kind of relationship anytime in their lives.

**2 missings

no Rio de Janeiro, encontraram $51,4 \%$ de casos de violência perpetrada na vida contra parceira, igualmente tendo na violência psicológica aquela de maior prevalência ${ }^{17}$. Esta violência contra a parceira representa, conforme estudos brasileiros com grupos focais de homens ${ }^{10,11}$, a imposição de uma autoridade sobre as mulheres e a submissão feminina nas relações afetivas, que se reflete em atos de humilhação, maus tratos, xingamentos e ameaças de outras agressões por parte dos homens, quando desapontados quanto aos afazeres domésticos, obrigações com filhos ou nas relações de casal. Muitas vezes se conjuga com a violência física, como também se constata no presente estudo. Na violência física foi encontrada taxa superior à referida na literatura, tanto brasileira $^{17}$, quanto de estudo realizado na África do Sul ${ }^{25}$, que constatou, entre homens de 15 a 26 anos, uma prevalência de $28,2 \%$. No entanto, essa taxa situa-se dentro do intervalo de variação das prevalências de 18 a $45 \%$ encontradas em inquérito populacional com homens de 18 a 65 anos na Índia ${ }^{26}$. Por outro lado, a violência sexual 

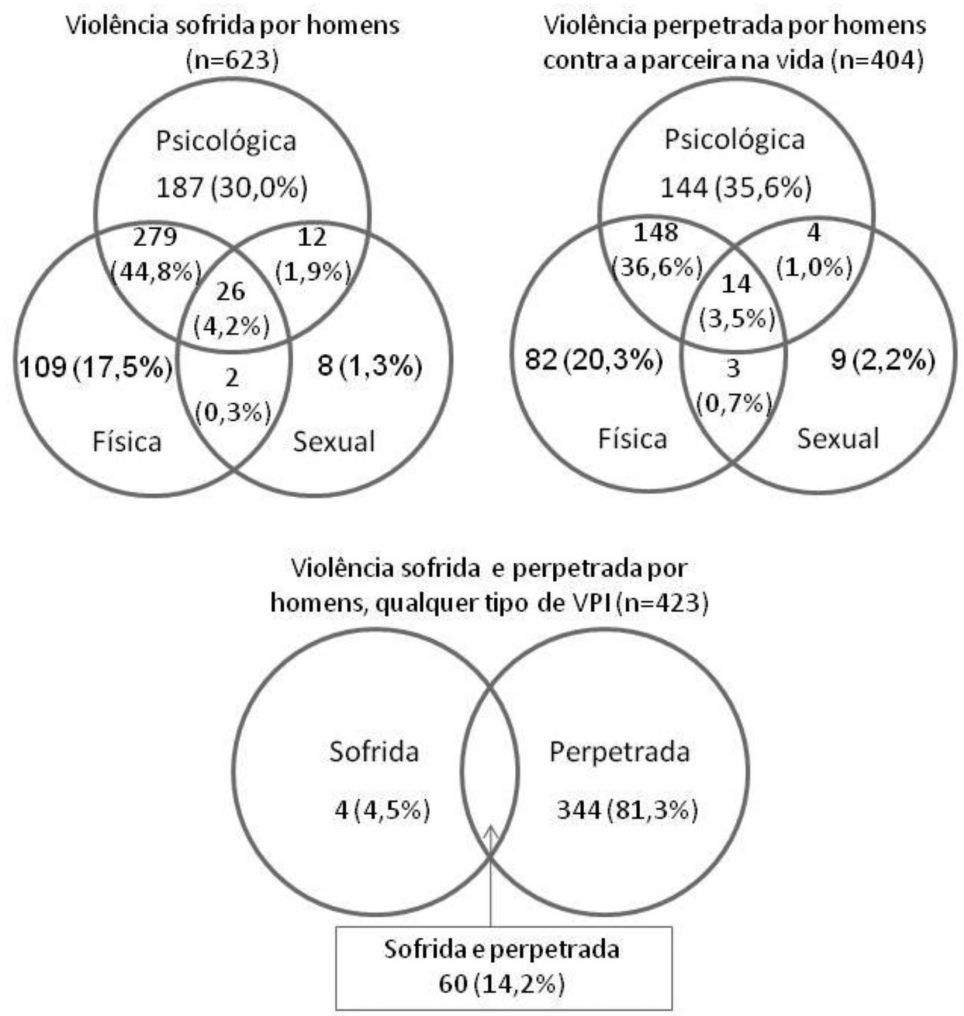

Figura 2 - Sobreposição das violências sofridas e perpetradas por homens. São Paulo, 2003. Figure 2 - Overlap of experienced and perpetrated violence by men São Paulo, 2003.

perpetrada contra a parceira na vida, de $3,9 \%$ neste estudo, foi a menos prevalente da literatura, considerando-se a variação de $18 \%$ a $40 \%$, no estudo indiano ${ }^{26}$ e a taxa de $9,3 \%$ no estudo sul-africano ${ }^{25}$, assim como em comparação com outro estudo realizado na África do Sul, que encontrou 15,3\% para os últimos dez anos ${ }^{27}$.

No que concerne à violência sofrida por qualquer agressor, o presente estudo também revelou uma prevalência geral bastante elevada, mas pelo fato agregar os três tipos de violência é pouco comparável com estudos internacionais, quase sempre voltados para a violência física ou a física e/ou sexual. Se considerarmos estes dois últimos tipos de violência, o presente estudo, com respectivamente $52,8 \%$ e $55,3 \%$, mostra taxas de menor magnitude que os dados apresentados em estudo americano de âmbito nacional (respectivamente, $66,4 \%$ e $66,8 \%)^{12}$. No entanto, a taxa de violência sexual $(6,1 \%)$ é o dobro da apresentada no estudo americano (3\%), explicando a maior diferença entre a violência física e/ou sexu$\mathrm{al}$, relativamente à física, do presente estudo frente ao americano.

Por outro lado, com referência à taxa geral de violência sofrida ora encontrada, percebe-se a relevância que o tipo psicológico representa no incremento das ocorrências no caso brasileiro. Recentes estudos sobre as masculinidades apontam para o sentimento de desvalorização que os homens sentem em razão de subalternidades para determinadas situações de classe e de raça ${ }^{28}$. Outros apontam os homens como alvo preferencial - em comparação com as mulheres - de depreciações por parte da polícia ${ }^{29,30}$. É interessante a situação relatada de humilhações que acontecem no ambiente de trabalho ${ }^{31}$ e que reitera os resultados deste estudo quanto aos agressores da violência sofrida, com taxas muito próximas aos estranhos, principal agressor no caso brasileiro, bem como no estudo americano 
de Tjaden e Thoennes ${ }^{12}$.

Já em relação à violência sofrida tendo por agressora a parceira íntima, a prevalência para qualquer tipo de violência encontrada neste estudo $(10,2 \%)$ é praticamente a metade das encontradas em estudos americanos, como o de Reid et al. ${ }^{32}$, com $28,8 \%$ e conduzido com usuários de serviços de saúde maiores de 18 anos; ou o populacional, realizado por Coker et al ${ }^{33}$, com homens entre 18 a 65 anos, com 22,9\%. Também para cada tipo de violência sofrida, neste estudo $9,2 \%$ psicológica, $7,1 \%$ física, $1 \%$ sexual e 7,9\% física e/ou sexual, essas taxas são menores que as da literatura americana, com $18,7 \%$ para a psicológica e $17,6 \%$ para a física e/ou sexual, entre usuários ${ }^{32}$, ou então $7 \%$ para a física na população masculina ${ }^{12}$. Mas em todos os estudos a violência psicológica persiste como a de maior magnitude. Já no caso da violência sexual, se a taxa ora encontrada ( $1,5 \%)$ é maior que a de $0,2 \%$ do estudo de Tjaden e Thoennes ${ }^{12}$, ela é bem menor que a de outro estudo brasileiro de $5,1 \%$, populacional, com a faixa etária de 16 a 65 anos, para Brasil urbano ${ }^{34}$. Essa diferença pode ser explicada por sub-revelação importante desse tipo de violência por parte dos homens entrevistados, uma vez que o foram como usuários do serviço em que se realizou a pesquisa, ou por diferença regional do contexto paulista, uma vez que o instrumento utilizado foi o mesmo.

No que tange à recorrência de episódios, não foram encontrados dados de outros estudos para serem contrastados com os atuais resultados. Chama a atenção que o perfil da violência perpetrada difere bastante do apresentado pela violência sofrida, o que provavelmente se deva pelo fato de a violência perpetrada se tratar daquela contra as parceiras, situação de grande intimidade. É contrastante que a violência física esteja praticamente em mesma proporção entre episódios únicos e repetidos, mas a sexual seja marcada pela repetição dos episódios. Já no caso da violência sofrida, a física é que se caracteriza pela repetição, enquanto a violência sexual pela situação única de ocorrência.
Esses resultados reiteram a marca da violência de gênero contra as mulheres, particularmente contra as parceiras íntimas, em que se destaca o contraste da violência sexual contra mulheres em comparação com aquelas sofridas pelos homens ${ }^{2,12,34}$, denotando que os homens são mais perpetradores da violência sexual contra as mulheres e da violência física entre pares homens. Mas essas diferenças podem também se dever a dificuldades de revelação da violência sexual sofrida pelos homens e, ademais, como violência de repetição.

Por fim, na superposição dos tipos psicológico, físico e sexual de violência, encontra-se uma grande proporção de tipos combinados, indicando ser a conjugação das violências o padrão de ocorrência quer no caso de violência sofrida, quer perpetrada contra a parceira. Observando-se, agora, a sobreposição das violências sofridas e praticadas, restritamente à violência entre parceiros íntimos, observamos as mulheres como agressoras menos usuais contra seus parceiros que os homens. Isto reforça o estudo de Tjaden e Thoennes ${ }^{12}$, que mostra, não só para a violência por parceiro íntimo, mas em geral, os homens como principais agressores das mulheres e dos outros homens. Estes resultados também indicam que os homens sofrem mais violência no espaço público e a perpetram mais no espaço doméstico, o que está de acordo com o estudo de Reed et al, ${ }^{35}$, que encontrou associação positiva significativa entre a vivência de violência contra parceiro intimo e o envolvimento em atos de violência na comunidade, em um estudo populacional desenvolvido com homens afrodescendentes nos Estados Unidos.

Rhodes et al. ${ }^{36}$ apontam para uma superposição de $10,8 \%$ entre violência por parceiros íntimos sofrida e praticada. Essa taxa é próxima dos $14,2 \%$ encontrados neste estudo, embora seja referente apenas à violência no último ano.

Na percepção das violências, tanto se observa taxa bem menor de considerar ter sofrido violência na vida (32,8\%), quanto de ter sido violento $(30,4 \%)$, frente às respostas 
afirmativas às questões que indagavam por atos praticados ou sofridos sem menção ao termo "violência". Também chama a atenção a taxa de considerar-se sofrendo violência ser próxima àquela de ser violento. Uma possível explicação seria que os homens concebem como violência apenas parte das situações experimentadas e relatadas de atos de agressões, abusos e humilhações, já que, de modo geral, tais atos são tidos como toleráveis por fazerem parte da construção de sua masculinidade, sobretudo nas relações com pessoas próximas ou conhecidas. Esse aspecto é reforçado por estudos qualitativos realizados com homens ${ }^{10,11}$, que mostram que, particularmente com relação à violência entre parceiros íntimos, os homens banalizam sua ocorrência. Já o termo violência, que designaria situações não usuais, passaria a significar apenas situações da vida pública ou de relações mais impessoais e relativamente anônimas.

\section{Considerações finais}

As características da violência sofrida e da perpetrada indicam o grande envolvimento dos homens com diversas situações, mutuamente reforçadas e recorrentes ao longo de suas vidas. Mostram a violência em praticamente todas as formas de suas relações sociais, embora eles nem sempre a reconheçam. Assim, os dados encontrados confirmam e são explicados pelos estudos de gênero, para os quais a violência é parte da socialização dos meninos, resultando em práticas futuras em seus exercícios de masculinidade na vida cotidiana. Introjetando a violência em seus processos de afirmação identitária de homens, essa referência de gênero os predispõe a perpetrá-la contra pessoas por eles consideradas inferiores na escala social, tais como mulheres, idosos, homossexuais, ou certos segmentos de classe ou raciais de seus pares ${ }^{24}$.

Se considerarmos a violência dos homens contra as mulheres, no interior da qual prepondera a praticada contra a parceira íntima, a abordagem de gênero levanta possibilidades interpretativas que vão desde uma maior associação entre machismo e violência ${ }^{5}$, à interpretação acerca das crenças internalizadas da maior autoridade dos homens em conexão com a noção de virilidade ${ }^{24,38} \mathrm{e}$ ao fato de a violência de gênero reagir às expectativas e às atuações dos homens. Este conjunto aponta para a representação da violência como prática de educar e aculturar o(a) parceiro(a) na "casa" e na "rua" ${ }^{37}$.

Por isso, seja nas relações afetivo-sexuais, seja nas relações públicas de sociabilidade, conformam-se situações extremamente perversas e nas quais o recurso à violência se justifica e se banaliza, produzindo impactos importantes na saúde dos homens e das mulheres e em suas demandas no interior dos serviços de saúde. É de extrema relevância, pois, que essas situações constituam objetos de futuros estudos e sejam alvo de medidas de atenção e prevenção no campo da Saúde.

\section{Referências}

1. Minayo MCS. A inclusão da violência na agenda da saúde: trajetória histórica. Rev Ciênc Saúde Coletiva 2006; 11(2): 375-84.

2. Schraiber LB, d'Oliveira APFL, Couto MT. Violência e saúde: estudos científicos recentes. Rev Saúde Públ 2006; 40(N Esp): 112-20.

3. Krug EG, Dahlberg LL, Mercy JA, Zwi AB, Lozano R (eds). World Report on violence and health. Geneva: World Health Organization; 2002.

4. Hong L. Toward a transformed approach to prevention: breaking the link between masculinity and violence. Am J Coll Health 2000; 48: 269-79.

5. Greig A. Troublesome Masculinities, 2005. Disponivel em http://www.alangreig.net/text/troublesomemasculinities/troublesome-masculinities/. [Acessado em 15 maio de 2011].

6. Castro R, Riquer F. La investigación sobre violencia contra las mujeres en América Latina: entre el empirismo ciego y la teoría sin datos. Cad Saúde Pública 2003; 19(1): 135-46. 
7. Fuller N. She made me go out of my mind: marital violence from the male point of view. Development 2001; 44(3): 25-9.

8. Diniz NMF, Lopes RL, Gesteira SM, Alves SL, Gomes NP. Violência conjugal: vivências expressas em discursos masculinos. Rev Esc Enferm USP 2003; 37(2): 81-8.

9. Gomes NP, Freire NM. Vivência de violência familiar: homens que violentam suas companheiras. Rev Bras Enferm 2005; 58(2): 176-9.

10. Couto MT, Schraiber LB, d’Oliveira AF, Kiss LB. Concepções de gênero entre homens e mulheres de baixa renda e escolaridade acerca da violência contra a mulher, São Paulo, Brasil. Ciênc Saúde Coletiva 2007; 11(S): 1323-32.

11. Rosa AG, Boing AF, Buchele F, Oliveira NF, Coelho EBS. A Violência conjugal contra a mulher a partir da ótica do homem autor da violência. Saúde Soc 2008; 17(3): 15260 .

12. Tjaden $\mathrm{P}$, Thoennes N. Prevalence and consequences of male-to-female and female-to-male intimate partner violence as measured by the national violence against women survey. Violence Against Women 2000; 6(2): 14261 .

13. Harwell TS, Spence MR. Population Surveillance for Physical Violence Among Adult Men and Women, Montana 1998. Am J Prev Med 2000; 19(4): 321-4.

14. Acierno R, Resnick HS, Kilpatrick DG. Health impact of interpersonal violence. 1: Prevalence rates, case identification, and risk factors for sexual assault, physical assault, and domestic violence in men and women. Behav Med 1997; 23(2): 53-64.

15. Coker AL, Derrick C, Lumpkin JL, Aldrich TE, Oldendick R. Help-seeking for Intimate Partner Violence and Forced sex in South Carolina. Am J Prev Med 2000; 19(4): 316-20.

16. Carrasco-Portiño M, Vives-Cases C, Gil-Gonzales D, Dardet CA. Qué sabemos sobre los hombres que maltratan a su pareja? Una revisión sistemática. Rev Pan Salud Publica/Pan Am J Public Health 2007; 22(11): 55-63.

17. Lima DC, Buchele F, Clímaco DA. Homens, gênero e violência contra a mulher. Saúde Soc 2008; 17(2): 69-81.

18. Couto MT, Schraiber LB. Homens, saúde e violência: novas questões de gênero no campo da saúde coletiva. In: Minayo MCS, Coimbra Jr CEA (org.). Críticas e atuantes. Ciências Sociais e Humanas em Saúde na América Latina. Rio de Janeiro, Ed. Fiocruz; 2005. p. 687706.

19. Schraiber LB, d'Oliveira AFPL, Falcão MTC, Hanada H, Kiss LB, Durand JG et al. Violência contra a mulher entre usuárias de serviços básicos de saúde da rede pública da Grande São Paulo. Rev Saúde Públ 2007; 41(3): 359-67.

20. Schraiber LB, d' Oliveira AFPL, França-Junior I, Diniz CSG, Portella AP, Ludermir AB et al. WHO: Multi Country Study on Women's Health and Domestic Violence against
Women, Brazil. [Relatório Científico]. São Paulo: Faculdade de Medicina da Universidade de São Paulo; 2002. Projeto WHO reference: W6/181/13.

21. Schraiber LB, Latorre MRDO, França-Junior I, Segri NJ, d' Oliveira AFPL. Validade do instrumento WHO-VAW Study para estimar violência de gênero contra a mulher. Rev Saúde Públ 2010; 44(4): 658-66.

22. Connell, R. The Role of Men and Boys in Achieving Gender Equality, 2003 Disponível em http:/ / www. un.org/womenwatch/daw/egm/men-boys2003/ Connell-bp.pdf. [Acessado em 15 de maio de 2011].

23. Schraiber LB, d'Oliveira APFL, França-Junior I, Diniz S, Portella AP, Ludermir AB et al. Prevalência da violência contra a mulher por parceiro íntimo em regiões do Brasil. Rev Saúde Pública 2007; 41(5): 797-807.

24. Nolasco S. De Tarzan a Homer Simpson. Banalização e violência masculina em sociedades contemporâneas ocidentais. Rio de Janeiro: Rocco; 2001.

25. Dunkle KL, Jewkes RK, Nduna M, Levin J, Jama N, Khuzwayo $\mathrm{N}$ et al. Perpetration of partner violence and HIV risk behaviour among young men in the rural Eastern Cape, South Africa. Aids 2006; 20(16): 2107-14.

26. Martin SL, Tsui AO, Maitra K, Marinshaw R. Domestic violence in northern India. Am J Epidemiol 1999; 150(4): 417-26.

27. Abrahams N, Jewkes R, Hoffman M, Laubsher R Sexual violence against intimate partners in Cape Town: prevalence and risk factors reported by men. Bull World Health Organ 2004; 82 (5): 330-7.

28. Nascimento, P. Não-provedores: desemprego e alcoolismo masculino em comunidades de baixa renda, 2005, 21p. Disponível em http://www6.ufrgs.br/ppgas/nucleos / naci/documentos/texto-pedro-premiocnpq-spm.pdf. [Acessado em 15 de maio de 2011].

29. Ramos S, Musumeci L. Elemento suspeito: abordagem policial e discriminação na cidade do Rio de Janeiro. Rio de Janeiro: Civilização Brasileira; 2005.

30. Machado E, Noronha C. A polícia dos pobres: violência policial em classes populares urbanas. Sociologias 2002; 4(7): 188-221.

31. Barreto, M. Violência, saúde e trabalho, uma jornada de humilhações. São Paulo: EDUC; 2003.

32. Reid RJ, Bonomi AE, Rivara FP, Anderson ML, Fishman PA, Carrell D, et al. Intimate Partner Violence Among Men: Prevalence, Chronicity, and Health Effects. Am J Prevent Med 2008; 34(6): 478-85.

33. Coker AL, Davis KE, Arias I, Desai S, Sanderson M, Brandt HM, et al. Physical and mental health effects of intimate partner violence for men and women. Am J Prevent Med 2002; 23(4): 260-8.

34. Schraiber LB, d'Oliveira AFPL, França-Junior I. Violência sexual por parceiro íntimo entre homens e mulheres no Brasil urbano, 2005. Rev Saúde Públ 2008; 42(S1): 127-37. 
35. Reed E, Silverman JG, Welles SL, Santana MC, Missner SA, Raj A. Associations between Perceptions and Involvement in Neighborhood Violence and Intimate Partner Violence Perpetration among Urban, African American Men. J Community Health 2009; 34: 328-35.

36. Rhodes KV, Houry D, Cerulli C, Strauss H, Kaslow NJ, McNutt LA. Intimate partner violence and comorbid Mental Health condition among urban male patients. Ann Fam Med 2009; 7(1): 47-55.
37. Suarez M, Machado LZ, Bandeira L. Violência, sexualidade e saúde reprodutiva. In: Galvão L, Días J. Saúde sexual e reprodutiva no Brasil. São Paulo: Hucitec; 1999. p. 277-309.

38. Fuller N. Reflexiones sobre el machismo em América Latina. In: Valdés T, Olavarría J (eds.). Masculinidades y equidad de género em América Latina. Santiago: FLASCO-Chile; 1998. p. 258-266.

Recebido em: 25/05/11 Versão final apresentada em: 14/12/11 Aprovado em: 12/01/12 